\title{
Editor's Note: Multidisciplinary Extensions of Analysis
}

This issue of DRJ presents an impressive range of methodological approaches to the analysis of dance materials stemming from distinctly different disciplinary contexts. Although there is no warrant for unity among these essays, the essays speak to each other on the basis of this disciplinary variety. It is, in some sense, an extension of the earlier "Dance, the Disciplines and Interdisciplinary" (DRJ 41/1 Summer 2009) toward multidisciplinarity. Multidisciplinary perspectives converge in the analysis of particular dances, the dancer's social and political as well as life situation, and/or the production of the dance as well as its philosophical underpinnings and underlying aesthetics. The present authors do not so much theorize the relation of dance to other disciplines or of dance studies to interdisciplinary methodologies per se, but actually practice them critically, demonstrating their use from a variety of disciplinary locations and critical-historical contexts.

In "Inheriting Dance's Alternative Histories," Kate Elswit writes from the position of a dance scholar who is also the dramturg of the work under discussion, Roni Nair's Future Memory based on Kurt Jooss's Dixit Dominus (1975), which was created for Lilavati Häger. Elswit brings together the description of the work as well as of its genesis, in which she has been actively engaged, with a reflection on the future potentials of re-viewing this solo, which was an intercultural experiment before its time. It seems to me that Elswit provides here a unique model for writing such accounts that are at once production histories, choreographic poetics in process of realization, and theoretical reflection on history and re-performance, all brought into dialogue with the complex temporalities and relationships at play in Dixit Dominus itself as a choreographic work.

Anusha Kedhar's "Flexibility and Its Bodily Limits: Transnational South Asian Dancers in an Age of Neoliberalism" engages with an auto-ethnographic dancer's discourse in the context of the theme of the dancer's work as labor. Kedhar re-corporealizes "flexibility," a key term in postmodern studies of globalization, diaspora, and late capitalism. What Kedhar refers to as "the corporeal dimensions of transnational labor and flexible citizenship" (p. 24) is applied to the non-British subject of South-Asian dance whose labor is required but also problematized in certain UK dance companies. Out of this situation, the author details the different strands of "flexibility" when applied to dance technique across a divide of tradition and innovation in the capitalist market-in sum, a unique form of work required of the dancer-combined with the necessities for temporary migration (negotiating border crossings under short notice, which involves another sort of flexibility). Kedhar stretches strategically the notion of flexibility itself in the life of the dancer.

Ryan Platt's "The Ambulatory Aesthetics of Yvonne Rainer's Trio A" constitutes an original reading of Yvonne Rainer's Trio A that is bound to be controversial. Although a careful reader of the dance and its peculiar texture (avowedly from the 1978 film exclusively), what is it that makes this reading diverge so significantly from others we are familiar with? Might it relate to the performance studies orientation of the analysis? One reviewer of this essay remarked: "I imagine that this piece could generate many further developments in thinking about Rainer's and indeed other contemporary choreography deriving from the terms and concepts that it sets out." The notion of an ambulatory 
aesthetic drawn initially from Michel de Certeau, but amplified through art historian and theorist Rosalind Krauss's discussion of the index and further references to photography and film theory certainly transports dance and dance theory into other disciplinary domains of interpretation, notably those of photography and film. Particularly interesting is the way in which the ambulatory is set against Rainer's notion of "pedestrian movement" as a general metaphor for walking.

Peter Dickinson's essay, “Textual Matters: Making Narrative and Kinesthetic Sense of Crystal Pite's Dance-Theatre," is written from the position of literary critic with a keen facility for observation of the movement event. Dickinson reflects on the pivots - a crucial term here-between text and movement in Crystal Pite's work. He explores not only the dramaturgical and choreographic structures Pite deploys, but also their effectiveness: the "doubleness" of textual and kinesthetic response called forth in the viewer by the works of Pite's company Kidd Pivot. Hence, the narrative invoked in the article's title is less about a narrative conception of choreographic poetics than about how we narrate our perception of dance-theater in interpretive criticism. For, actually, Dickinson argues for the productive interaction of a kinesthetic register of language with a linguistic register of movement. The post-performance temporality of the text in Dickinson's account resonates with Elswit's awareness of hetero-temporalities in the re-production of Dixit Dominus.

Aili Bresnahan works from the basis of philosophical aesthetics in her "Improvisational Artistry in Live Dance Performance as Embodied and Extended Agency." In addition to making claims for improvisational artistry as "agency" — rather than thinking-Bresnahan draws on Andy Clark's embodied and extended mind theory. Although distinctly philosophical in its domain of reflection, this essay amplifies the notion of improvisation in performance both in terms of its instances of appearance and its relation to cognition. William Forsythe has spoken of visceral thinking as part of the dancer's toolbox, but what is actually meant by thinking is open to question: here, thinking is reformulated as agency, which brings to mind other conceptual extensions of danced experience in these essays: flexibility, walking, and kinesthetic textuality and textual kinesthetics.

Mark Franko

Editor, Dance Research Journal 